\title{
Preliminary Study on the Influence of Different Carbonation Curing Processes on Binders Based on Magnesium Oxide-Rich Powder Blended with Tungsten Mining Waste Mud
}

\section{Erick Grünhåuser Soares and João Castro-Gomes}

C-MADE - Centre of Materials and Building Technologies, University of Beira Interior - Faculty of Engineering, R. da Calçada Fonte Lameiro 10, 6200-358 Covilhã, Portugal

\section{Abstract}

In this preliminary study, the effect of the pre-drying stage, water immersion, carbonation curing cycles, and/or drying stage on carbonation curing of magnesium oxide-rich powder (MRP) was investigated. In addition, a blend of tungsten mining waste mud (TMWM) with MRP was also evaluated. The MRP and TMWM used have maximum grain sizes of $125 \mu \mathrm{m}$. The cement pastes were produced with 0 and 50 of TMWM weight

Corresponding Author: Erick Grünhäuser Soares e.grunhauser@ubi.pt

Received: 20 March 2020 Accepted: 30 April 2020 Published: 13 April 2020

Publishing services provided by Knowledge E

(c) Erick Grünhäuser Soares and João Castro-Gomes. This article is distributed under the terms of the Creative Commons

Attribution License, which permits unrestricted use and redistribution provided that the original author and source are credited.

Selection and Peer-review under the responsibility of the RICON19 - REMINE International Conference Conference Committee.

\section{G OPEN ACCESS} percentage. The specimens were compacted into cylindric moulds $(\varnothing=20 \mathrm{~mm} ; \mathrm{h}=$ $40 \mathrm{~mm}$ ) under $30 \mathrm{MPa}$ and, subsequently, submitted to five different processes of curing involving a pre-drying stage before carbonation, rapid water immersion cycles, additional drying periods, and different carbonation curing periods. The atmosphere of the pressurized carbonation curing chamber was controlled to provide a $\mathrm{CO}_{2}$ concentration of $>99 \%$, the partial pressure of $1 \mathrm{bar}$ and temperature of $60^{\circ} \mathrm{C}$. The influence of the curing processes on the compressive strength of each mix was determined 12 hours after the carbonation curing period. This study demonstrates that the water content during the curing process plays an important role in the increase of the hardening process and on the compressive strength.

Keywords: Carbonation curing, magnesium oxide, mining waste, curing processes, magnesium-based cement

\section{Introduction}

The level of anthropogenic greenhouse gas emissions is higher than ever. This level has increased since the pre-industrial era, mainly due to the economic and population growth and the last four decades comprise half of the anthropogenic $\mathrm{CO}_{2}$ emitted between 1750 and 2011 [1]. In the midst of this, the cement industry is responsible for approximately $7 \%$ of the $\mathrm{CO}_{2}$ emissions worldwide [2]. Therewith, the need to mitigate the $\mathrm{CO}_{2}$ emissions linked to the conventional cement production allied to the concerns 
on the climate changes has given some popularity to magnesium-based cements, mainly over the last decade [3]. In this scope, one of the main types of magnesiumbased cement is the reactive magnesia cement (RMC), which the literature describes as a blend of reactive $\mathrm{MgO}$ powder with conventional PC systems [3]. Such cement class is based on the carbonation cure for compressive strength gain, where the magnesium oxide $(\mathrm{MgO})$ hydrates forming brucite, which is subsequently carbonated turning into hydrated magnesium carbonates (HCM), such as nesquehonite, hydromagnesite, and dypingite [4]. Some MgO-based cements have many properties that are superior to those of ordinary Portland cement (OPC), such as: good resistance to fire; high early strength; match very well to a wide variety of inorganic and organic aggregates, like gravel, marble flour, sand, sawdust [5], asbestos, wood particles and expanded clays [6]. Allied to it, there is the advantage of $\mathrm{CO}_{2}$ activated binders, which have the potential to transform waste into building construction material, to store $\mathrm{CO}_{2}$ permanently and also stop these resources from ending in landfills [7].

It is important to know the factors that control the carbonation reactions and also understand how it affects its kinetics. Such factors have a great influence on its efficiency and two of them are temperature and partial pressure since the atmosphere's temperature influences the $\mathrm{CO}_{2}$ sequestration level, which enhances until the temperature reaches $60^{\circ} \mathrm{C}$ [8], and a high atmosphere partial pressure allows the $\mathrm{CO}_{2}$ to enter more easily into the cementitious interior matrix before occurring the precipitation of carbonates, thus contributing to the improvement of $\mathrm{CO}_{2}$ diffusivity in the cementitious matrix. [9-11].

Therefore, in this preliminary study, the influence of the water content on the carbonation curing was investigated and a method of pre-drying treatment and water immersion cycles were proposed aiming to improve the carbonation curing efficiency on magnesium oxide-rich powder (MRP) as well on a blend of tungsten mining waste mud (TMWM) with MRP, to access their effect on the hardening process and the compressive strength. For this purpose, five different curing processes were executed on two different mixes (one with 100\% MRP and other with 50\% MRP and 50\% TMWM). The use of TMWM is supported since this waste comes from Panasqueira mines, an important mine located in the Beira Interior region, Portugal, which has been operating for over 125 years. It produces huge amounts of waste daily which come mainly from mining tungsten. Such wastes have the potential to be considered a new raw material since the industrial applications are not limited by the cost of its production and/or transportation [12]. In addition, some studies demonstrate that TMWM from Panasqueira mines can be used as raw material on cementitious blends with other different technologies [13, 14]. 


\section{Materials and Methods}

\subsection{Materials}

The magnesium oxide-rich powder (MRP) used is a calcinated magnesia, whose commercial name is "Magal P", supplied by Invivo nSA, which is mainly used as an animal feed additive. Before being used, the received material was grinded in a ball mill grinder and sieved to obtain particles of a diameter size under $125 \mu \mathrm{m}$.

The Tungsten Mining Waste Mud (TMWM) was obtained by collecting it from the Panasqueira mine mud waste deposits. Before being used, the TMWM was disaggregated and sieved in order to obtain particles of diameter sizes under $125 \mathrm{~mm}$.

To determine the chemical compositions of MRP and TMWM, Energy-dispersive X-ray spectroscopy (SEM-EDX) tests on a Hitachi S-3400N apparatus were conducted, where three different spots were randomly selected on each material sample to obtain their chemical compositions, which are presented in Table 1.

The Loss on ignition (LOI) of MRP and TMWM were obtained by simultaneous thermogravimetric and differential scanning calorimetry (TG-DSC) using a TA Instrument SDT Q-50 apparatus. The MRP lost approximately $1.82 \%$ of its weight, while the TMWM lost about $11.34 \%$ of its weight at the temperature of $1000^{\circ} \mathrm{C}$ as it is shown in Table 1.

To obtain the Blaine fineness of MRP and TMWM, three tests in each sample of the raw material were conducted in an Acmel Labo BSA1 apparatus according to BS EN 196-6 [15], and then the average value was calculated. The Blaine specific area of MRP $\left(918 \mathrm{~cm}^{2} / \mathrm{g}\right)$ is slightly higher than TMWM $\left(850 \mathrm{~cm}^{2} / \mathrm{g}\right)$.

The particle size analyses were carried out in accordance with BS 1377-2:1990 by sedimentation using the hydrometer method [16]. The particle size distribution curve is presented in Fig. 1. The D50 of MRP is equal to $14.5 \mu \mathrm{m}$ and D50 of TMWM is $19.5 \mu \mathrm{m}$.

\subsection{Mix design}

The mix compositions of all prepared pastes are detailed in Table 2. The weight percentage (wt. \%) of MRP varies from 100\% to 50\% while the TMWM varies from $0 \%$ to $50 \%$. By contrast, the water to solid (w/s) ratio was kept constant in 0.25 . 
TABLE 1: Chemical composition (\%) and physical property of raw materials.

Chemical composition (\%) and physical property

$\mathrm{SiO}_{2}$

$\mathrm{Al}_{2} \mathrm{O}_{3}$

$\mathrm{Fe}_{2} \mathrm{O}_{3}$

$\mathrm{CaO}$

$\mathrm{MgO}$

$\mathrm{K}_{2} \mathrm{O}$

$\mathrm{Na}_{2} \mathrm{O}$

$\mathrm{SO}_{3}$

$\mathrm{TiO}_{2}$

$\mathrm{ZnO}$

Loss on ignition (\%)

Specific gravity $\left(\mathrm{g} / \mathrm{cm}^{3}\right)$

Specific surface area $\left(\mathrm{cm}^{2} / \mathrm{g}\right)$

$\mathrm{D}_{50}(\mathrm{~mm})$

\begin{tabular}{|c|c|}
\hline \multicolumn{2}{|c|}{ Material } \\
\hline MRP & TMWM \\
\hline 6.36 & 46.67 \\
\hline 1.38 & 17.05 \\
\hline 3.12 & 15.47 \\
\hline 3.36 & 0.69 \\
\hline 85.78 & 4.83 \\
\hline- & 4.9 \\
\hline- & 0.8 \\
\hline- & 7.9 \\
\hline- & 0.6 \\
\hline- & 1.09 \\
\hline 1.82 & 11.34 \\
\hline 3.45 & 3.19 \\
\hline 918 & 850 \\
\hline 0.0145 & 0.0195 \\
\hline
\end{tabular}

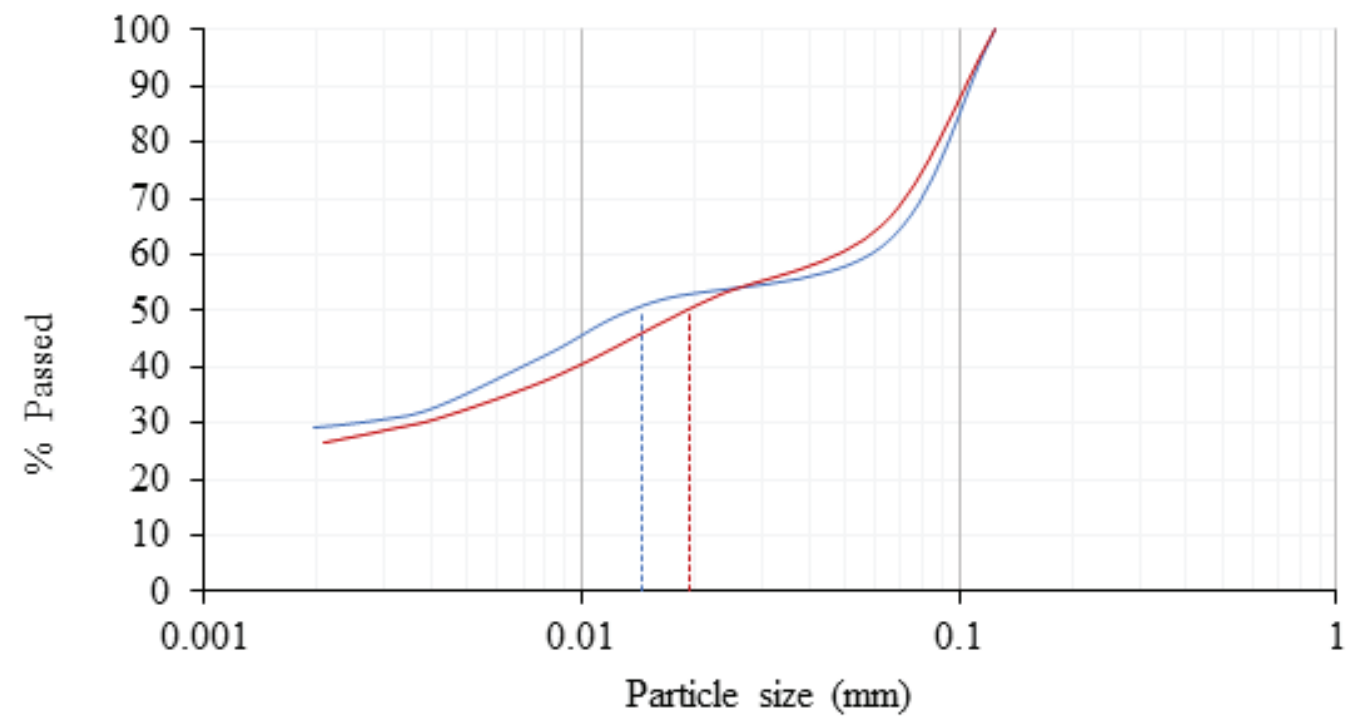

MRP D50 (MRP) TMWM D50 (TMWM)

Figure 1: Particle size analyses of raw materials 
TABLE 2: Mix labels

\begin{tabular}{|c|c|c|}
\hline Mix design & \multicolumn{2}{|c|}{ Weight (\%) } \\
\hline MRP & TMWM \\
\hline TMWM00C & 100 & 0 \\
\hline TMWM50C & 50 & 50 \\
\hline
\end{tabular}

\subsection{Specimens preparation}

The MRP and TMWM were mixed until it resulted in a homogeneous powder and then the liquid was gradually added into the mixture until a uniform paste was achieved. Later, the prepared paste was compacted into cylindric moulds ( $\varnothing=20 \mathrm{~mm}$; h=40 mm) using $30 \mathrm{MPa}$ of static compaction pressure. During the static compaction stage, part of the water present in the mix is expelled, thus reducing significantly the water content on the moulded specimens. Finally, the moulded specimens were subjected to five different $\mathrm{CO}_{2}$ curing processes.

\subsection{Sample's weight and water content}

The water content was determined before starting the curing processes. The water content of the fresh moulded specimens produced was determined using an electronic moisture meter KERN MLB_N apparatus, while the weight measurement of the moulded specimens was carried out by a precision balance readability of $0.01 \mathrm{~g}$, which has been taken the medium value of four specimens.

\subsection{Pre-drying stage preliminary study}

To understand the influence of a pre-drying stage (PDS) on the hardening process, several moulded specimens of TMWMOOC were submitted into an oven for a PDS, during different drying periods $\left(0,15,30,45\right.$ and 60 minutes) at $60^{\circ} \mathrm{C}$ and afterwards submitted to carbonation curing for 2 hours at controlled atmosphere $\left(\mathrm{CO}_{2}\right.$ concentration > 99\%; partial pressure $=1 \mathrm{bar}$; temperature $=60^{\circ} \mathrm{C}$ ). Thereafter, those specimens were broken longitudinally, the core was analysed, as well as the specimen's water content. Among these, the specimens submitted to 45 min of pre-drying stage exhibited an uniformly distributed and best-hardened core, showing a less lose powder quantity inside the core. In these specimens, the water content reduced from $13.60 \%$ (before PDS) to $10.9 \%$ 
after 45 min of PDS (Table 3). Thus, based on this preliminary study a PDS of 45 min was adopted in this study.

TABLE 3: Pre-drying stage preliminary study

Time $(\mathbf{m i n})$
0
15
30
45
60

\begin{tabular}{|c|c|}
\hline \multicolumn{2}{|c|}{ Water content } \\
\hline Initial & Final \\
\hline $13.60 \%$ & $13.6 \%$ \\
\hline & $12.6 \%$ \\
\hline & $11.2 \%$ \\
\hline & $10.9 \%$ \\
\hline & $8.2 \%$ \\
\hline
\end{tabular}

\subsection{Curing processes}

Five different curing processes were adopted. On the curing process 1 (CP1), the samples, after being moulded, were subjected to a carbonation curing period (CC) of $6 \mathrm{~h}$. The curing process 2 (CP2) involves a PDS for 45 min followed by CC of $6 \mathrm{~h}$. The curing process 3 (CP3) comprises a PDS for $45 \mathrm{~min}$ and a $\mathrm{CC}$ for $2 \mathrm{~h}$, followed by one cycle of water immersion (WI) for 5 seconds and CC for $4 \mathrm{~h}$. The curing process 4 (CP4) introduces the second cycle of WI and CC, which embraces a PDS for 45 min and a $\mathrm{CC}$ for $2 \mathrm{~h}$, followed by two subsequent cycles of $\mathrm{Wl}$ for 5 seconds and $\mathrm{CC}$ for $2 \mathrm{~h}$. The curing process 5 (CP5) introduces the drying stage (DS) after water immersion, which embraces a PDS for $45 \mathrm{~min}$ and a CC for $2 \mathrm{~h}$, followed by two subsequent cycles of $\mathrm{WI}$ for 5 seconds and CC for $2 \mathrm{~h}$. However, if the specimen's weight after WI is higher than the specimen's weight after PDS, then the specimen is submitted to DS to lose the extra water content obtained on the water immersion cycle. Every carbonation curing processes was done at controlled atmosphere $\left(\mathrm{CO}_{2}\right.$ concentration $>99 \%$; partial pressure $=1 \mathrm{bar}$; temperature $=60^{\circ} \mathrm{C}$ ).

Thereafter, the specimens were preserved on room conditions (temperature $20 \pm$ $2{ }^{\circ} \mathrm{C}$; relative humidity $\pm 60 \%$ ) for 12 hours until being tested. The control specimens (TMWMOOC) were prepared to provide a comparison with specimens that have $50 \%$ of TMWM on its weight composition. 
TABLE 4: Carbonation curing processes

$\begin{aligned} & \text { Curing } \\ & \text { process }\end{aligned}$
CP1
CP2
CP3
CP4
CP5

\begin{tabular}{|c|}
\hline PDS \\
\hline- \\
\hline $45 \mathrm{~min}$ \\
\hline $45 \mathrm{~min}$ \\
\hline $45 \mathrm{~min}$ \\
\hline $45 \mathrm{~min}$ \\
\hline
\end{tabular}

\begin{tabular}{|l}
\hline $\mathrm{CC}$ \\
$6 \mathrm{~h}$ \\
$6 \mathrm{~h}$ \\
$2 \mathrm{~h}$ \\
\hline $2 \mathrm{~h}$ \\
\hline $2 \mathrm{~h}$ \\
\hline
\end{tabular}
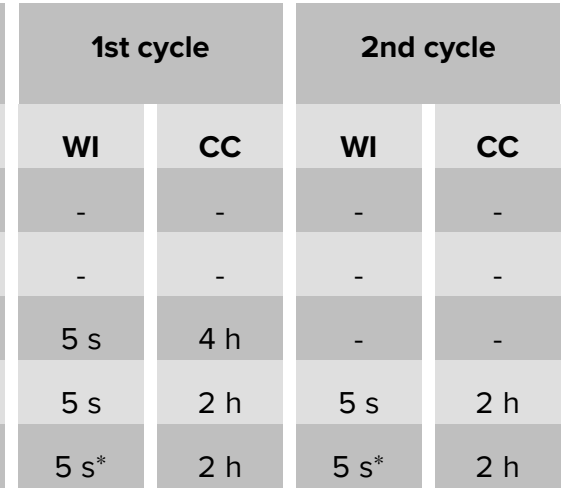

* Followed by drying stage (DS)
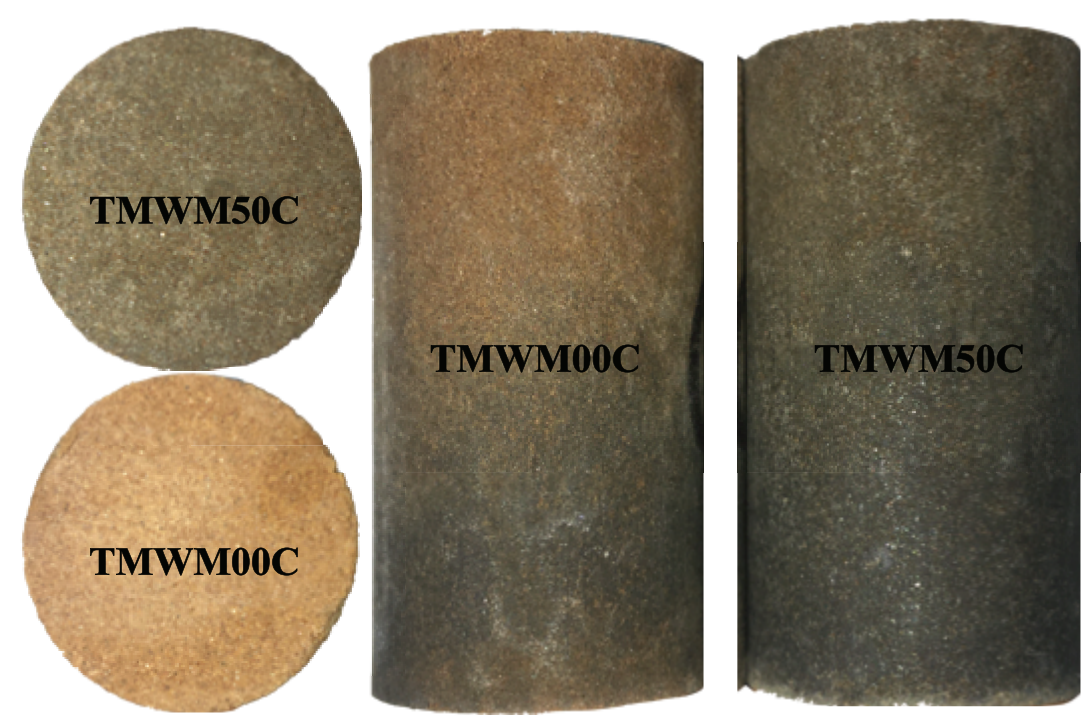

Figure 2: Specimens of TMWMOOC and TMWM50C soon after the CP5

\subsection{Compressive strength}

The compressive strength tests occurred $12 \mathrm{~h}$ after the carbonation curing of 6 hours, which were measured by uniaxial loading in triplicates on the two mix compositions of the five curing processes. The equipment used was an ADR Touch 3000 BS EN Compression Machine with Digital Readout and Self Centring Platens, operated at a constant loading rate of $0.5 \mathrm{kN} / \mathrm{sec}$.

\section{Results and Discussion}




\subsection{Water content}

The TMWMOOC presented $11.5 \%$ as initial water content, while the TMWM50C presented $13.9 \%$. The PDS decreased the water content by $1 \%$ on TMWMOOC and $0.8 \%$ on TMWM50C.

It was noticed that during the carbonation curing of TMWMOOC only the $\mathrm{CC}$ of the $2^{\text {nd }}$ cycle on the CP5 did not present loss of water content. So, it is assumed that the atmosphere medium could be saturated which in turn has inhibited the loss of water from the specimen TMWMO0C-CP5 on the last curing cycle. The specimen TMWM50CCP5 also presents a similar behaviour, but in this case, it has presented a gain of water content on the $\mathrm{CC}$ of the $1^{\text {st }}$ and on the $2^{\text {nd }}$ cycle on the CP5.

Every specimen has shown loss of water content $12 \mathrm{~h}$ after the curing process has finished. Such behaviour indicates that the specimens still hold excess free water on themselves after carbonation curing.

The highest loss of water content after carbonation curing that happens on TMWMOOC occurred in CP3, while on TMWM50C occurred in CP2.

The results are summarized in Table 5 and Table 6, and in Fig. 3 and Fig. 4.

TABLE 5: TMWMOOC water content by curing process (\%)

\begin{tabular}{|c|c|c|c|c|c|c|c|}
\hline \multicolumn{3}{|c|}{ Curing process } & CP1 & CP2 & CP3 & CP4 & CP5 \\
\hline \multicolumn{3}{|l|}{ Initial } & \multicolumn{5}{|l|}{11.5} \\
\hline \multicolumn{3}{|l|}{ PDS } & - & 10.5 & 10.6 & 10.6 & 10.4 \\
\hline \multicolumn{3}{|l|}{ cc } & 9.8 & 9.7 & 9.9 & 9.8 & 9.7 \\
\hline \multirow[t]{6}{*}{ Cycle } & $\mathbf{1}^{s t}$ & WI & - & - & 10.8 & 10.6 & 10.8 \\
\hline & & DS & - & - & - & - & 10.3 \\
\hline & & CC & - & - & 9.6 & 9.7 & 9.6 \\
\hline & $2^{\text {nd }}$ & WI & - & - & - & 10.6 & 10.4 \\
\hline & & DS & - & - & - & - & 10.3 \\
\hline & & CC & - & - & - & 10.0 & 10.5 \\
\hline \multicolumn{3}{|c|}{$12 \mathrm{~h}$ after curing } & 9.4 & 9.5 & 9.3 & 9.5 & 10.3 \\
\hline
\end{tabular}

\subsection{Compressive strength}

The specimens cured by carbonation curing achieved compressive strengths up to 29.7 $\mathrm{MPa}$, where the best compressive strength belongs to the specimen TMWMOOC-CP2. The compressive strength of the specimens that were submitted to CP3 and CP4 was 
TABLE 6: TMWM50C water content by curing process (\%)

\begin{tabular}{|c|c|c|c|c|c|c|c|}
\hline \multicolumn{3}{|c|}{ Curing process } & CP1 & CP2 & CP3 & CP4 & CP5 \\
\hline \multicolumn{3}{|l|}{ Initial } & \multicolumn{5}{|l|}{13.9} \\
\hline \multicolumn{3}{|l|}{ PDS } & - & 13.2 & 13.1 & 12.9 & 13.1 \\
\hline \multicolumn{3}{|l|}{ CC } & 13.4 & 12.8 & 11.9 & 12.1 & 11.9 \\
\hline \multirow[t]{6}{*}{ Cycle } & $\mathbf{1}^{s t}$ & WI & - & - & 14.0 & 14.0 & 14.1 \\
\hline & & DS & - & - & - & - & 12.9 \\
\hline & & CC & - & - & 13.3 & 13.4 & 13.5 \\
\hline & $\mathbf{2}^{\text {nd }}$ & WI & - & - & - & 14.5 & 14.2 \\
\hline & & DS & - & - & - & - & 13.4 \\
\hline & & CC & - & - & - & 13.4 & 14.0 \\
\hline \multicolumn{3}{|c|}{$12 \mathrm{~h}$ after curing } & 13.0 & 12.7 & 12.8 & 12.7 & 13.5 \\
\hline
\end{tabular}

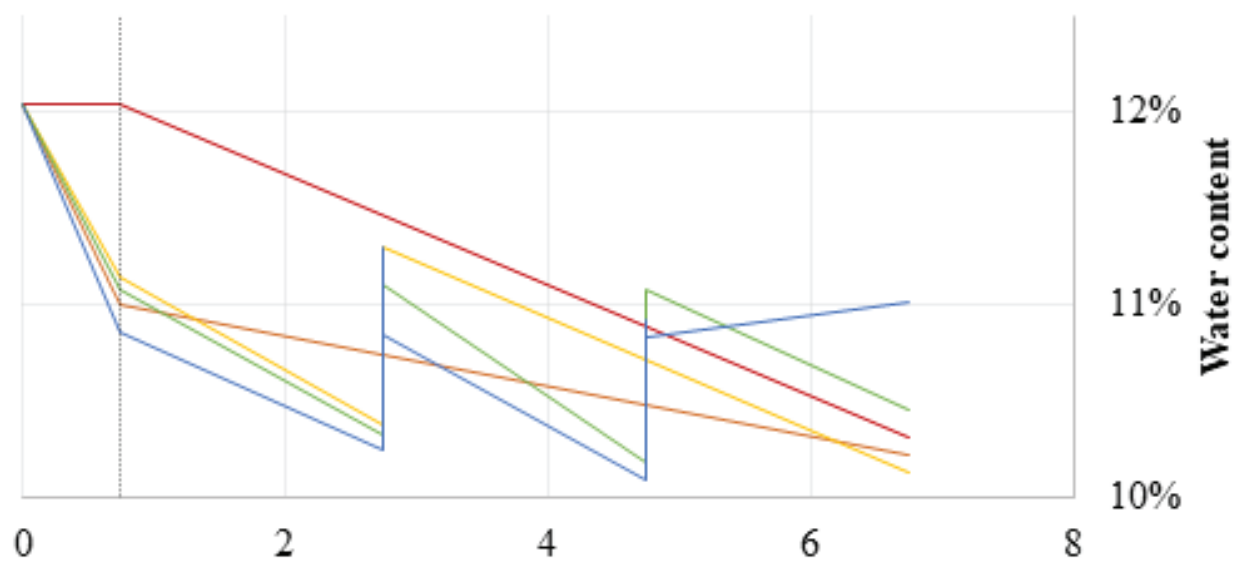

Time (h)

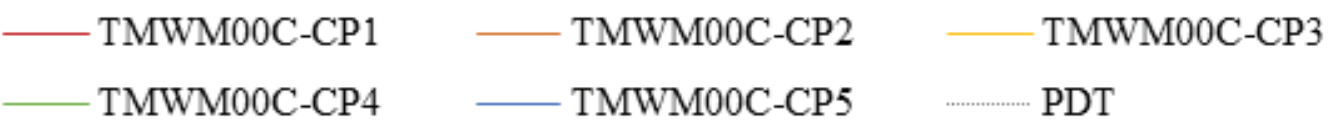

Figure 3: TMWMOOC water content along the time (\%)

lower than the minimum value that could be read. On the other hand, the specimens TMWMOOC and TMWM5OC of CP1, CP2, and CP5 compressive strength are presented in Fig. 5, which shows the comparison of compressive strength of the composition of different blends versus the curing process which was submitted.

The specimen TMWMOOC suggests that the MRP reacts with the water present in the mix and also with the $\mathrm{CO}_{2}$. Such behaviour was already expected since the $\mathrm{MgO}$ present on MRP reacts with water forming magnesium hydroxide $\left(\mathrm{Mg}(\mathrm{OH})_{2}\right)$, which reacts with dissolved $\mathrm{CO}_{2}$ on the water forming hydrated magnesium carbonates (HMCs) [4]. 


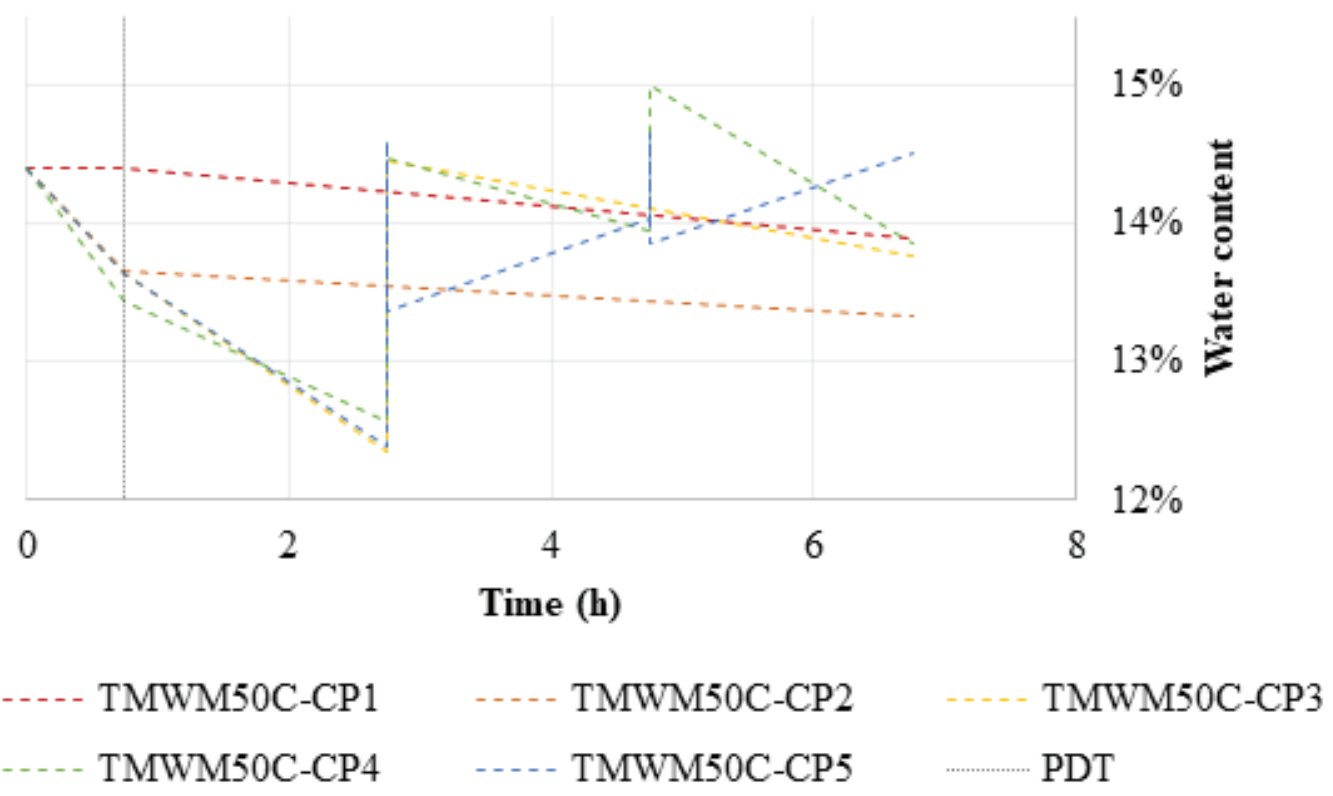

Figure 4: TMWM50C water content along the time (\%)

The PDS shows that this stage improves the compressive strength of the proposed mix labels since both presented a strength gain after PDS.

The excess of water content does not collaborate with the gain of strength since the specimens which received the WI step and were not followed by the DS (CP3 and CP4), presented compressive strength lower than the equipment can read. On the other hand, if the excess of water is controlled, as it was done in CP5, the compressive strength increases if compared with CP3 and CP4.

The compressive strength of CP1 and CP5 has not presented a significant difference.

The mix designs have not presented a significant effect on the compressive strength (reduction less than $15 \%$ for $50 \%$ wt. \% of TMWM), therefore it may assume that the carbonation conditions have much more influence on the compressive strength of the binders produced than the addition of $50 \mathrm{wt}$. \% of TMWM. Thus, it may suppose that part of the MgO present in the mixes has not reacted.

\section{Conclusions and Future Studies}

This preliminary study has evaluated the carbonation reaction and hardening of a series of specimens of magnesium oxide-rich powder (MRP) and tungsten mining waste mud (TMWM) at different moisture conditions during carbonation curing. The water content was analysed, as well as the compressive strength of 100\% MRP and 50\% MRP $+50 \%$ 


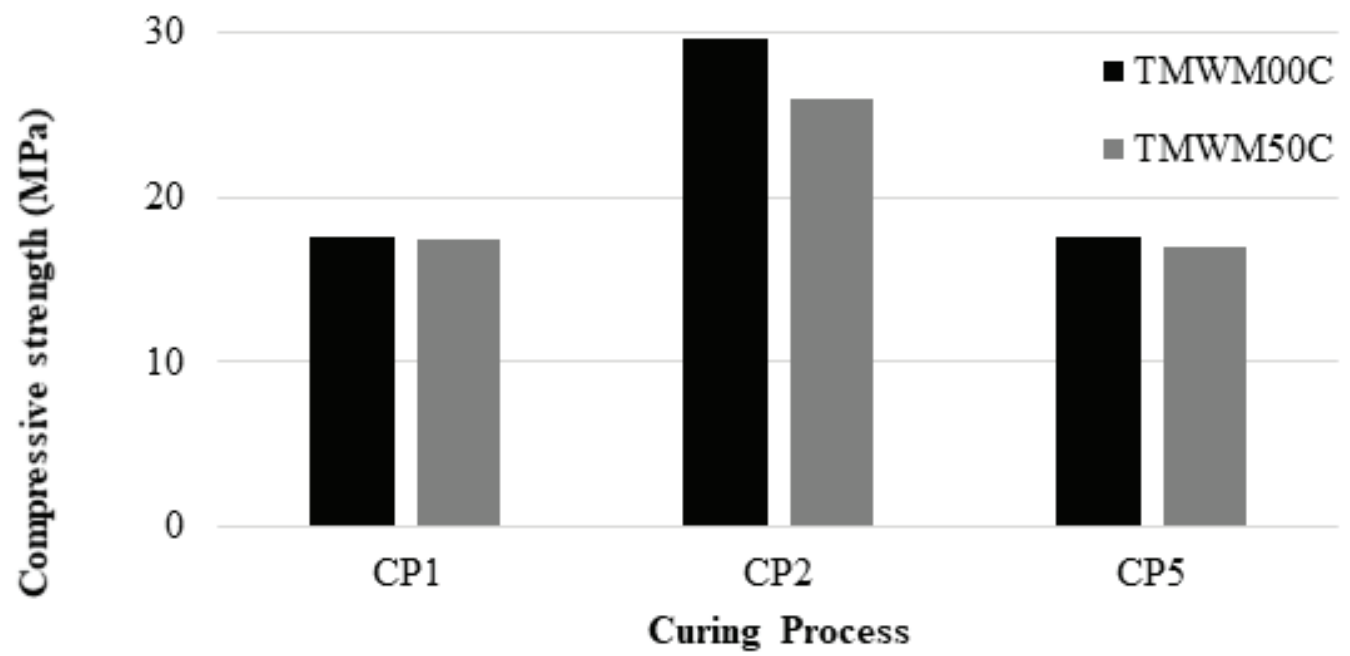

Figure 5: Comparison of compressive strength versus curing process on TMWMOOC and TMWM50C

TMWM blends produced on five different curing processes. Therefore, the results of this study are summarized below:

1. Initial water content, as well as the water content during the curing process, plays an important role in carbonation curing and consequently on compressive strength.

2. The carbonation processes conditions had more influence on the compressive strength than the addition of $50 \mathrm{wt}$ \% of TMWM, since the compressive strength difference between the mix designs are lower than 15\%. Thus it suggests that part of the $\mathrm{MgO}$ present in the mixes had not reacted.

3. The excess of not controlled water content is inadequate to carbonation curing since the specimens submitted to CP3 and CP4 demonstrated it.

4. Initial PDS reveals itself beneficial for water content control since CP2 presented higher compressive strength than CP1 and the only difference between these curing processes is that the PDS is present on CP2;

5. The DS executed on CP5 also reveals itself beneficial for water content control since the only difference between the CP4 and CP5 curing processes is that the DS is present on CP5;

6. The method of carbonation process (CP5) proposed and executed to control the water content during carbonation curing that consists of PDS, WI followed by CC cycles and DS, is a promising way to control the water content on specimens during the carbonation curing process; 
7. The highest compressive strength was achieved on the specimen TMWMOOC-CP2, which reached 29.7 MPa, followed by TMWM50C-CP2, which reached $26 \mathrm{MPa}$.

Therefore, based on the compressive results obtained in the current work, the magnesium oxide-rich powder (MRP) used is a promising cementitious binder material in which the compressive strength is related to the carbonation curing process. Besides that, it may represent an alternative way to make hybrid binders containing other mineral powders materials, such as tungsten mining waste mud (TMWM). Finally, the binders produced may represent an effective way to incorporate a wide variety of wastes, and at the same time, capture and store $\mathrm{CO}_{2}$ into cementitious materials. However, future studies are necessary to understand better the binders produced in this work.

\section{Acknowledgements}

This work was partially financed by Portuguese national funds through FCT - Foundation for Science and Technology, IP, within the research unit C-MADE, Centre of Materials and Building Technologies (CIVE-Central Covilhã-4082), University of Beira Interior, Portugal.

\section{References}

[1] IPCC, (2014). Climate Change 2014: Synthesis Report. Contribution of Working Groups I, II and III to the Fifth Assessment Report of the Intergovernmental Panel on Climate Change [Core Writing Team, R.K. Pachauri and L.A. Meyer (eds.)]. IPCC, Geneva, Switzerland, 151 pp.

[2] International Energy Agency, (2018), Technology Roadmap: Low-Carbon Transition in the Cement Industry, 1-66. doi:10.1007/SpringerReference_7300.

[3] Walling, S.A. and Provis, J.L. (2016). Magnesia-Based Cements: A Journey of 150 Years, and Cements for the Future?. Chem. Rev., vol. 116, pp. 4170-4204.

[4] Sonat, C., Lim, C.H., Liska, M. and Unluer, C. (2017). Recycling and reuse of reactive MgO cements - A feasibility study. Constr. Build. Mater., vol. 157, pp. 172-181.

[5] Shand, M.A. (2006). The Chemistry and Technology of Magnesia. (Hoboken: John Wiley \& Sons).

[6] Li, Z. and Chau, C.K. (2007). Influence of molar ratios on properties of magnesium oxychloride cement. Cem. Concr. Res., vol. 37, pp. 866-870.

[7] Humbert, P.S. and Castro-Gomes, J. (2018). $\mathrm{CO}_{2}$ activated steel slag-based materials: A review. J. Clean. Prod., vol. 208, pp.448-457. 
[8] Liu, L.,et al. (2001). Development of a $\mathrm{CO}_{2}$ solidification method for recycling autoclaved lightweight concrete waste. J. Mater. Sci. Lett., vol. 20, pp. 1791-1794.

[9] Mo, L., et al. (2016). Effectiveness of using CO 2 pressure to enhance the carbonation of Portland cement-fly ash-MgO mortars. Cem. Concr. Compos., vol. 70. pp. 78-85.

[10] Bernal, S.A. et al. (2014). Natural carbonation of aged alkali-activated slag concretes. Mater. Struct., vol. 47, pp. 693-707.

[11] Bukowski, J.M. and Berger, R.L. (1979). Reactivity and strength development of $\mathrm{CO}_{2}$ activated non-hydraulic calcium silicates. Cem. Concr. Res., vol. 957-68.

[12] Castro-Gomes, J. (2017). Materiais Reciclados por Ativação Alcalina. Rev. Mater. Construção Da Assoc. Port. Das Empres. Mater. Construção. pp. 36-40.

[13] Sedira, N. and Castro-Gomes J., (2020). Effect of activators on hybrid alkaline binder based on tungsten mining waste and ground granulated blast furnace slag. Constr. Build. Mater., vol. 232.

[14] Beghoura, I. and Castro-Gomes, J. (2019). Design of alkali-activated aluminium powder foamed materials for precursors with different particle sizes. Constr. Build. Mater., vol. 224, pp. 682-690.

[15] British Standard, (1992). BS EN 196-6:1992. Methods of testing cement. Determination of fineness. British Standards Institution. London UK.

[16] British Standard, (1990). BS 1377-2: 1990. Methods of test for soils for civil engineering purposes. Classification tests. British Standards Institution. London UK. 